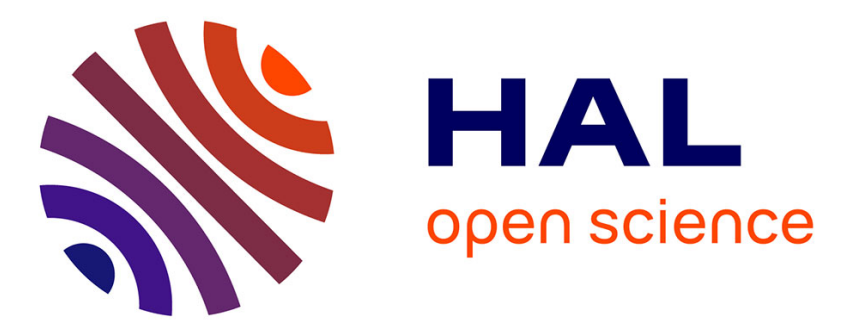

\title{
In-Situ Surface Analysis of SOFC Cathode Degradation Using High Temperature Environmental Scanning Electron Microscopy
}

\author{
M. Niania, Renaud Podor, S. Skinner, J. Kilner
}

\section{- To cite this version:}

M. Niania, Renaud Podor, S. Skinner, J. Kilner. In-Situ Surface Analysis of SOFC Cathode Degradation Using High Temperature Environmental Scanning Electron Microscopy. ECS Transactions, 2015, 68 (1), pp.665-670. 10.1149/06801.0665ecst . hal-02000076

\section{HAL Id: hal-02000076 \\ https://hal.umontpellier.fr/hal-02000076}

Submitted on 29 Apr 2019

HAL is a multi-disciplinary open access archive for the deposit and dissemination of scientific research documents, whether they are published or not. The documents may come from teaching and research institutions in France or abroad, or from public or private research centers.
L'archive ouverte pluridisciplinaire HAL, est destinée au dépôt et à la diffusion de documents scientifiques de niveau recherche, publiés ou non, émanant des établissements d'enseignement et de recherche français ou étrangers, des laboratoires publics ou privés. 


\title{
In-situ Surface Analysis of SOFC Cathode Degradation using High Temperature Environmental Scanning Electron Microscopy \\ M. A. Niania ${ }^{a}$, R. Podor ${ }^{\mathrm{b}}$, S. J. Skinner ${ }^{\mathrm{a}}$, and J. A. Kilner ${ }^{\mathrm{a}}$ \\ ${ }^{a}$ Department of Materials, Imperial College London, London SW7 2AZ, UK \\ ${ }^{\mathrm{b}}$ Institut de Chimie Séparative de Marcoule, Site de Marcoule, Bâtiment 426 BP 17171 F-30207 Bagnols sur Cèze Cedex, France
}

\begin{abstract}
In this study the surface properties of LSCF have been studied insitu from room temperature to $1000^{\circ} \mathrm{C}$ using a High Temperature Environmental Scanning Electron Microscope (HT-ESEM) under a number of different atmospheres. Dense, polished $\mathrm{La}_{0.6} \mathrm{Sr}_{0.4} \mathrm{Co}_{0.2} \mathrm{Fe}_{0.8} \mathrm{O}_{3-\delta}$ (LSCF) was observed during thermal annealing under a vacuum, pure oxygen, pure water and humid air atmospheres. The effect each atmosphere had on the surface morphology has been characterized in real time and analysed chemically using EDX. Significant differences in the surface behaviour were seen under each atmosphere. The results observed in the HT-ESEM were complimentary to surface exchange measurements performed in air and have enabled a more detailed understanding of SOFC cathode decomposition.
\end{abstract}

\section{Introduction}

SOFCs convert gaseous fuels, e.g. $\mathrm{H}_{2}$, into electricity through an electrochemical process. Their conversion efficiencies are not limited by the Carnot cycle and pollution levels in the exhaust gas are significantly lower than that of traditional technologies. SOFC cathode materials require a very precise balance of material properties in order to function. They must have suitable electronic and ionic conductivity to facilitate the reduction of oxygen and incorporation of oxygen ions into the system, but must also have matching thermal expansion and chemical compatibility with the electrolyte at operating temperatures $\left(\sim 600-800^{\circ} \mathrm{C}\right)$. A number of systems fulfil these requirements, but there are numerous challenges these materials face during manufacture and operation. Of particularly concern is the negative impact secondary phase formation at the surface has on the reduction of oxygen.

In a large number of perovskite systems used for SOFC cathodes the A-site is occupied by lanthanum $\left(\mathrm{La}^{3+}\right)$. This is often doped with strontium $\left(\mathrm{Sr}^{2+}\right)$ to introduce charge carrying species and oxygen vacancies through charge compensation, which generates ionic conductivity. The B-site atoms are typically transition metals and are widely assumed to be the primary atoms facilitating oxygen reduction as they exhibit multiple valence states. Therefore it is preferable for B-site atoms to terminate the surface. However, numerous sources studying many different systems have reported evidence of strontium segregation to the surface [1-4]. It is believed that the charge difference between the lanthanum and strontium in AO layers changes the state of the B transition metals (i.e. $\mathrm{B}^{2+/ 3+}$ ) to preserve charge neutrality and in turn creates dipole moments between $\mathrm{AO}$ and $\mathrm{BO}_{2}$ layers (see Fig. 1). This creates an alternating electric field through the material, leaving a large surface charge, which the system attempts to reduce by depleting the surface of lanthanum and segregating strontium. 


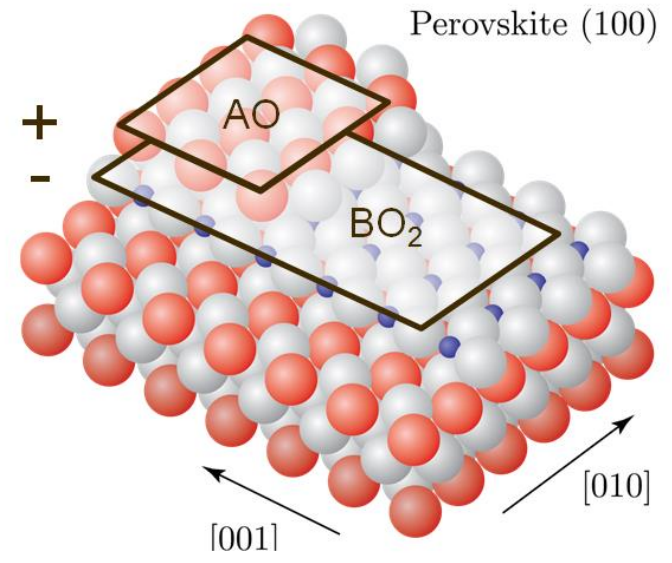

(a)

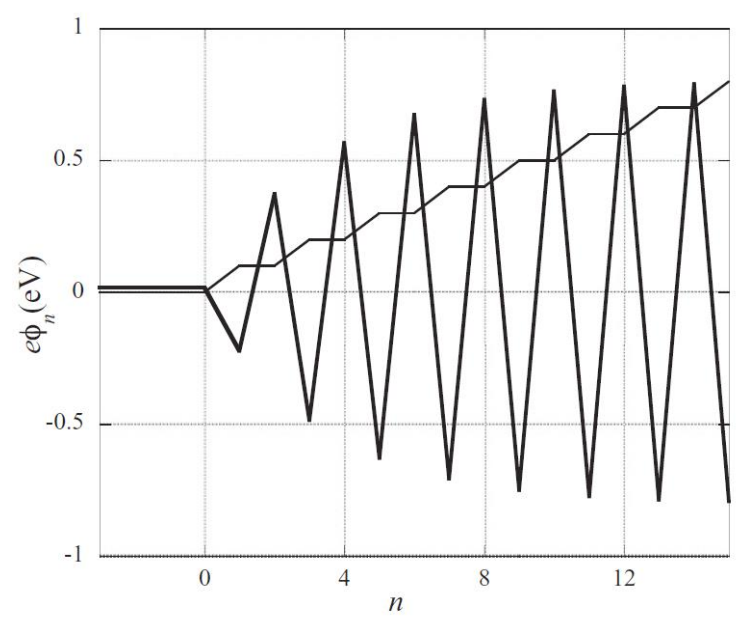

(b)

Figure 1. (a) Showing the perovskite structure with (100) termination and the alternating $\mathrm{AO} / \mathrm{BO}_{2}$ layers and dipole moment between them, and (b) potential as a function of plane number from the surface (heavy line shows the potential and the light line shows the strength of the internal electric field) recreated from [5]

The effect this decomposition has on oxygen reduction is not well understood. Numerous papers report decreased cell performance due to decomposition of the cathode [6]-[8]; however, Isotopic Exchange (IE) data obtained recently (see Fig. 2) has shown that the decomposition of the surface can in fact increase surface exchange properties. There are a number of possible explanations, such as increased surface area due to roughening effects, but this have not yet been quantified.

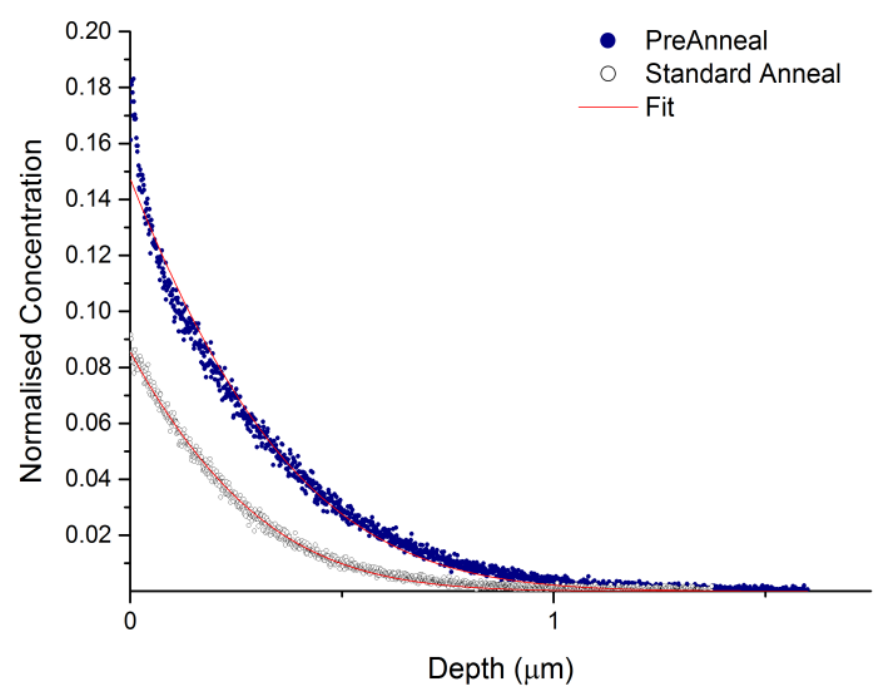

Figure 2. Showing diffusion profiles for LSCF samples 'pre-annealed' for 1 hour at $1000^{\circ} \mathrm{C}$ (to induce surface decomposition) before exchanging and a standard diffusion profile obtained using the IEDP method. 


\section{Experimental}

\section{Sample Preparation}

Samples of dense $\mathrm{La}_{0.6} \mathrm{Sr}_{0.4} \mathrm{Co}_{0.2} \mathrm{Fe}_{0.8} \mathrm{O}_{3-\delta}$ (LSCF) were produced from powders provided by Praxair Specialty Ceramics. A pellet was pressed uniaxially under 2 tonnes of pressure in a $10 \mathrm{~mm}$ die before being pressed isostatically under $300 \mathrm{MPa}$. The green pellet was then sintered at $1250^{\circ} \mathrm{C}$ for 8 hours using a $300^{\circ} \mathrm{C} /$ hour heating rate. Using the Archimedes method for measuring relative density it was found that this pellet was $97 \%$ dense. The samples were cut into multiple pieces approximately $2 \times 2 \times 1 \mathrm{~mm}(\mathrm{~W} \times \mathrm{H} \times$ D).

All samples were marked appropriately using a diamond tipped scribe to allow for easy location of a specific area of the sample during SEM analysis.

\section{$\underline{\text { HT-ESEM Analysis (Quanta } 200 \text { ESEM FEG) }}$}

The polished samples were observed under the following heating regimes and atmospheres, at 5,000x and 10,000x magnification:

1. RT to $1000^{\circ} \mathrm{C}$ with $300^{\circ} \mathrm{C} / \mathrm{hr}$ heating rate and an hour isotherm at $1000^{\circ} \mathrm{C}$ under vacuum $\left(\sim 10^{-4} \mathrm{mbar}\right)$

2. RT to $1000^{\circ} \mathrm{C}$ with $300^{\circ} \mathrm{C} / \mathrm{hr}$ heating rate and an hour isotherm at $1000^{\circ} \mathrm{C}$ under $3.5 \mathrm{mbar}$ pure $\mathrm{O}_{2}$

3. RT to $1000^{\circ} \mathrm{C}$ with $300^{\circ} \mathrm{C} / \mathrm{hr}$ heating rate and an hour isotherm at $1000^{\circ} \mathrm{C}$ under $3.5 \mathrm{mbar}$ pure $\mathrm{O}_{2}$ on the same area as the EBSD analysis

4. RT to $1000^{\circ} \mathrm{C}$ with $300^{\circ} \mathrm{C} / \mathrm{hr}$ heating rate and an hour isotherm at $1000^{\circ} \mathrm{C}$ under $3.5 \mathrm{mbar}$ pure $\mathrm{H}_{2} \mathrm{O}$

5. RT to $1000^{\circ} \mathrm{C}$ with $300^{\circ} \mathrm{C} / \mathrm{hr}$ heating rate and an hour isotherm at $1000^{\circ} \mathrm{C}$ under $3.5 \mathrm{mbar}$ air

EDX analysis was carried out to determine the chemical composition of certain features. This required a change in detector within the ESEM and as such samples were cooled and exposed to the atmosphere whilst switching the detectors.

\section{$\underline{\text { Isotopic Exchange }}$}

One well established method of studying the kinetics of oxygen reduction in oxygen ion conductors is Isotopic Exchange Depth Profiling (IEDP) [9]. The technique employs the use of an isotopic tracer $\left({ }^{18} \mathrm{O}\right)$ that is chemically identical, but can be discerned from the abundant isotope due to its different mass. By exchanging diffusion profiles of the tracer isotope it becomes possible to measure them using a mass spectrometry technique such as Secondary Ion Mass Spectrometry (SIMS). An analytical solution to the scenario of diffusion in a semi-infinite medium with surface evaporation was derived by Crank. Least squares fitting of the experimental profiles to Crank's solution allows the determination of the equilibrium diffusion $(D)$ and surface exchange $(k)$ coefficients [10],[11]. 


\section{Results and Discussion}

The primary result from this experiment is the differences observed in the surface decomposition under the various atmospheres.

\section{$\underline{\text { Pure } \mathrm{O}_{2}}$ Anneal (3 mbar)}

As can be seen in Fig. 3 the evolution of the surface occurs in three distinct stages: (1) the exsolution of precipitates on a number of grain boundary triple points, (2) the thermal etching of the grain boundaries and defects induced during polishing and (3) the growth of rod shaped strontium and oxygen containing precipitates on both the grain boundaries as well as the centre of the grain. It is clear that the $\mathrm{Sr}$ containing precipitates appear to grow with crystallographic direction as, within each grain, they tend to orientate themselves in a similar direction. Unusually, some grain surfaces populate with precipitates more quickly than others, but they will eventually populate given time. During the isotherm at $1000^{\circ} \mathrm{C}$ the precipitates do not continue to grow or coarsen over time.

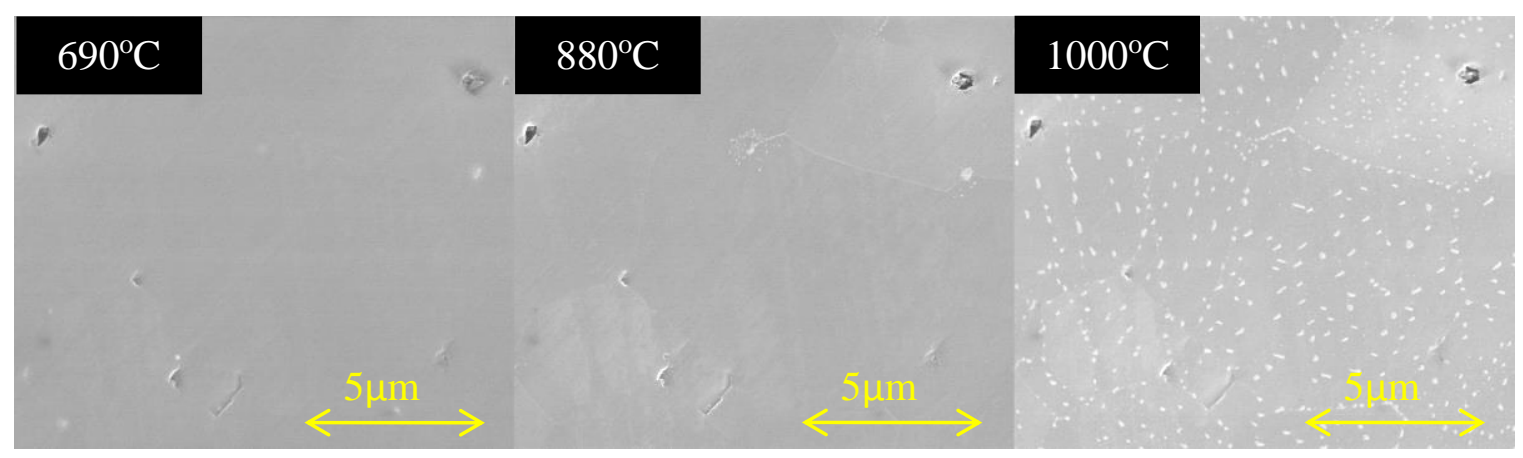

Figure 3. Three micrographs at increasing time/temperature intervals of an LSCF sample annealed in pure $\mathrm{O}_{2}$

\section{$\underline{\text { Pure } \mathrm{H}_{2} \mathrm{O} \text { Anneal (3mbar) }}$}

As can be seen in Fig. 4 the evolution of the surface in pure water behaves significantly differently. In this regime there are two distinct stages of growth: (1) the etching of both the grain boundaries and centre of the grains and (2) the rapid growth of strontium containing precipitates that continue to grow unhindered during the $1000^{\circ} \mathrm{C}$ isotherm. Two distinct precipitates can be seen at this point; the large strontium precipitates, but a darker secondary phase. EDX was used to determine that these were cobalt rich precipitates. Interestingly, some of these Co rich precipitates appear to be below the larger strontium containing precipitates and some appear to be 'engulfed' by them. This could suggest that the Co rich precipitates grew first and were then the nucleation sites for the strontium containing precipitates. 


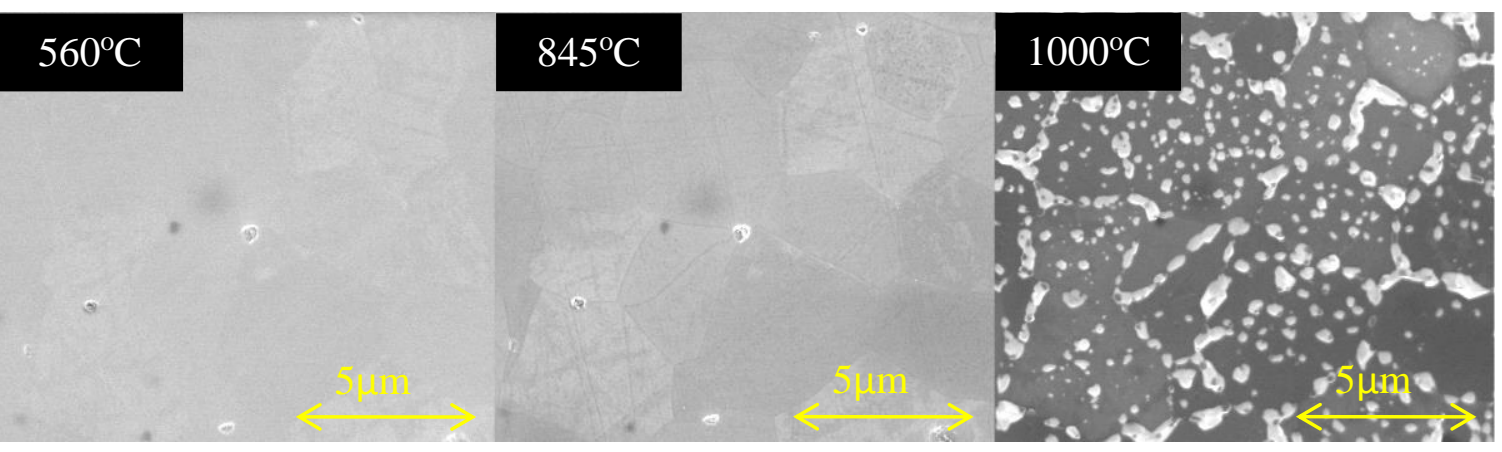

Figure 4. Three micrographs at increasing time/temperature intervals of an LSCF sample annealed in pure $\mathrm{H}_{2} \mathrm{O}$

\section{Air Anneal (3 mbar)}

Compressed lab air was used for this experiment. The measured humidity was approximately $60 \%$ temperature at $21^{\circ} \mathrm{C}$. As can be seen in Fig. 5 the evolution of the surface in air does not behave in the same way as either the pure $\mathrm{O}_{2}$ or pure $\mathrm{H}_{2} \mathrm{O}$ experiment. There are some consistencies, such as the growth of Co rich phases on the grain boundaries and within the grains, however, the growth of $\mathrm{Sr}$ containing precipitates appears to be significantly reduced on both the centre of the grains and the grain boundaries/defects even during the $1000^{\circ} \mathrm{C}$ isotherm. This strongly suggests that other components and contaminants of air, such as carbon dioxide and sulphur dioxide, inhibit the growth of the precipitates by the formation of a passivating layer.

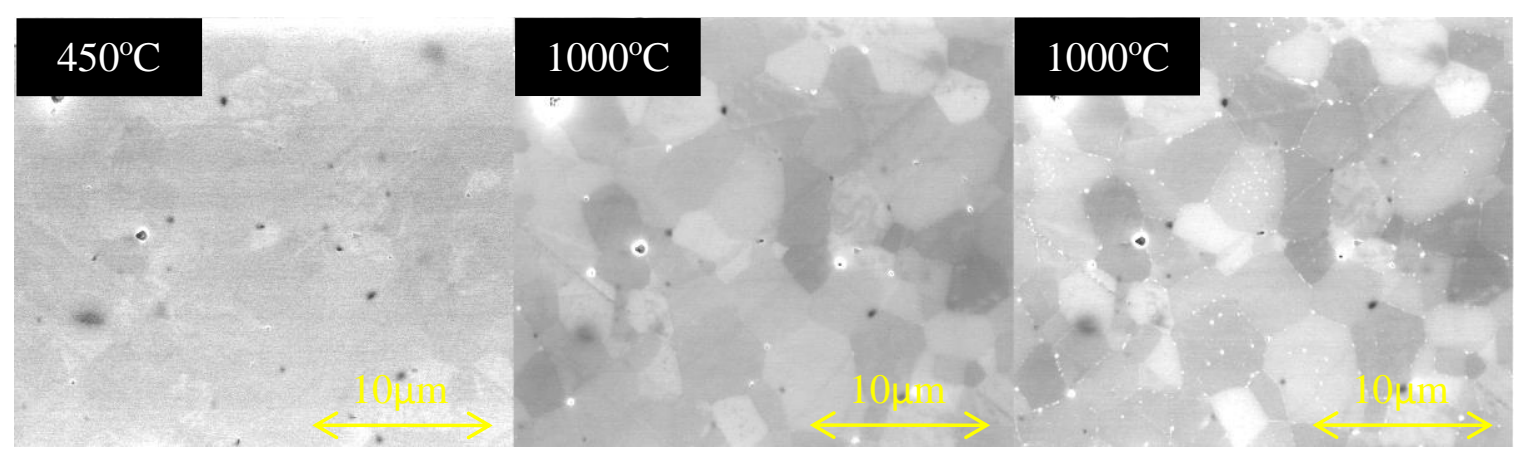

Figure 5. Three micrographs at increasing time/temperature intervals of an LSCF sample annealed in air. The third micrograph shows the surface after the one hour isotherm at $1000^{\circ} \mathrm{C}$

$\underline{\text { Vacuum Anneal }\left(\sim 1 \times 10^{-4} \text { mbar }\right)}$

As can be seen in Fig. 6 the vacuum anneal has certain similarities to the pure $\mathrm{O}_{2}$ anneal. Precipitates appear to grow on the grain boundaries/defects and in the centre of the grains at approximately the same time. Some of the precipitates on the grain boundary appear to coarsen during the isotherm. EDX analysis confirmed that the smaller particles are cobalt rich precipitates and the coarsened particles are strontium containing. This would suggest the growth of strontium precipitates can also occur in reducing environments 


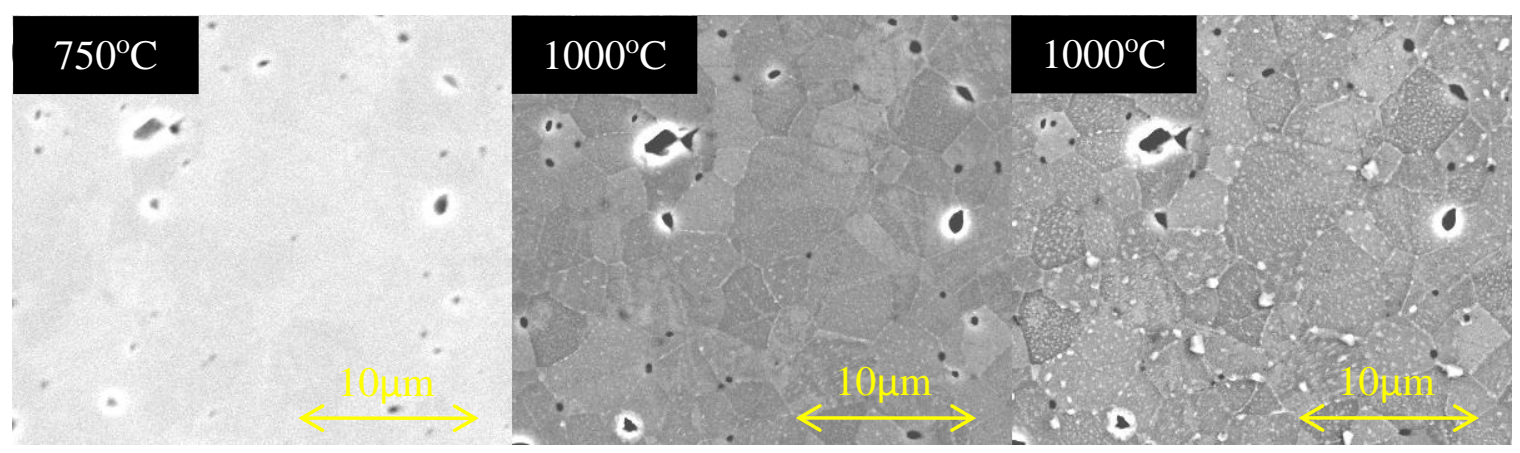

Figure 6. Three micrographs at increasing time/temperature intervals of an LSCF sample annealed in a vacuum. The third micrograph shows the surface after the one hour isotherm at $1000^{\circ} \mathrm{C}$

\section{Conclusions and Future Work}

In this work we have clearly documented the direct effect of a vacuum, pure oxygen, pure water and air atmospheres on the morphology and chemistry of the surface of LSCF. It is clear, not just from this study, that perovskite based cathode materials decompose in oxidising atmospheres, but this work has also shown that decomposition also occurs in a reducing environment. The main similarity between each of the atmospheres is the presence of cobalt precipitates and the nature of their formation. Strontium precipitation is significantly enhanced under a water atmosphere, however, in air the precipitation appears to be limited by the presence of the other gases.

One observation is that growth of the precipitates varies from grain to grain. In order to characterise the changes Electron Backscattered Diffraction (EBSD) will be carried out on a known area. This area will then be observed during the same annealing conditions as carried out in this experiment to correlate grain orientation to growth rates. In doing so the stability of the surface in relation to the crystallographic termination will be able to be characterised.

\section{Acknowledgments}

MN would like to thank Institut de Chimie Séparative de Marcoule and Dr Renaud Podor for continued help and contribution for the collection and analysis of HT-ESEM data. Thanks are also in order to EPSRC (EP/J003085/1) for funding this work.

\section{References}

1. D. Oh, D. Gostovic, and E. D. Wachsman, J. Mater. Res., 27, 1992-1999 (2012).

2. M. Kubicek, A. Limbeck, T. Frömling, H. Hutter, and J. Fleig, J. Electrochem. Soc., 158, B727 (2011).

3. A.-K. Huber, Phys. Chem. Chem. Phys., 14, 751-8 (2012).

4. J. Druce, T. Ishihara, and J. Kilner, Solid State Ionics, 262, 893-896 (2014).

5. W. A. Harrison, Phys. Rev. B, 83, 155437 (2011). 
6. E. Bucher and W. Sitte, Solid State Ionics, 192, 480-482 (2011).

7. M. Yang, E. Bucher, and W. Sitte, J. Power Sources, 196, 7313-7317 (2011).

8. E. Bucher, C. Gspan, F. Hofer, and W. Sitte, Solid State Ionics, 238, 15-23 (2013).

9. R. J. Chater, S. Carter, J. A. Kilner, and B. C. H. Steele, Solid State Ionics, 53-56, 859-867 (1992).

10. J. Kilner, B. Steele, and L. Ilkov, Solid State Ionics, 12, 89-97 (1984).

11. J. Crank, The Mathematics of Diffusion, $2^{\text {nd }}$ ed. p. 414, (1975). 